\title{
Benign Fibrous Histiocytoma of the Left Tenth Rib
}

Mehta $\mathbf{M}^{1^{*}}$, Brown $\mathbf{R}^{2}$, Tsui $\mathbf{A}^{3}$ and Antippa $\mathbf{P}^{4}$

${ }^{1}$ Thoracic Fellow, Royal Melbourne Hospital, VIC, Australia

${ }^{2}$ Cardiothoracic Surgeon, Royal Melbourne Hospital, VIC, Australia

${ }^{3}$ Pathologist, Royal Melbourne Hospital, VIC Australia

${ }^{4}$ Lung Tumour Services, Royal Melbourne Hospital, VIC Australia

*Corresponding author: Marzi Mehta, Thoracic Fellow, Royal Melbourne Hospital, VIC, Australia, Tel: +61 393427000; E-mail: marzimehta1975@gmail.com

Received date: Mar 17, 2017; Accepted date: Apr 13, 2017; Published date: Apr 20, 2017

Copyright: (c) 2017 Mehta M, et al. This is an open-access article distributed under the terms of the Creative Commons Attribution License, which permits unrestricted use, distribution, and reproduction in any medium, provided the original author and source are credited.

\begin{abstract}
We report a case of benign fibrous Histiocytoma of the left tenth rib in a 40-year-old man. CT revealed an expanding lesion with calcification. An open biopsy of the lesion was performed and subsequently wide surgical resection of the left 10 th rib was performed. Histological diagnosis was consistent with benign fibrous Histiocytoma of the rib.
\end{abstract}

Keywords: Benign Fibrous Histiocytoma (BFH); Giant cell tumour; Plasmacytoma; Malignancy

\section{Introduction}

Benign Fibrous Histiocytoma (BFH) of the bone is a rare tumor which most commonly involves the wing of the ilium and long bones. Patients range from 5 to 75 years in age and no sex predilection has been noticed. Until recently $\mathrm{BFH}$ was considered to be a variant of metaphyseal fibrous defect (including fibrous cortical defect, nonossifying fibroma etc.).

$\mathrm{BFH}$ of the rib is an extremely rare entity, and very few reports have been published in literature.

\section{Case Presentation}

We present a case of a 40 year old male with history of left sided chest pain for two months. He did not have any history of trauma. Local examination did not suggest any skin changes and there was no palpable mass. The diagnostic imaging ( $\mathrm{X}$ ray chest and CT Thorax) was suggestive of a solitary expansile lesion of the left 10th rib. Computed Tomography (CT) scan of thorax revealed a well-defined lytic bone lesion.

The tumour originated from the middle portion of the left 10th rib. The lung fields, mediastinum, and pleura were normal. The remaining scan did not show any other obvious bony abnormality. The differential (Figure 1) diagnosis made on CT scan was: Giant Cell Tumour (GCT); Plasmacytoma; and Benign Fibrous Histiocytoma (BFH).

He underwent biopsy of the rib lesion to confirm pathology and rule out a metastatic lesion. The biopsy was BFH of the rib for which he subsequently underwent resection of the left 10th rib. Part of 10th rib containing (Figures 2 and 3 ) the residual tumour (BFH) was excised by achieving a $2 \mathrm{~cm}$ margin on either side. Grossly the tumour showed two fragments of a rib $45 \times 20 \times 10 \mathrm{~mm}$ and $40 \times 35 \times 17 \mathrm{~mm}$.

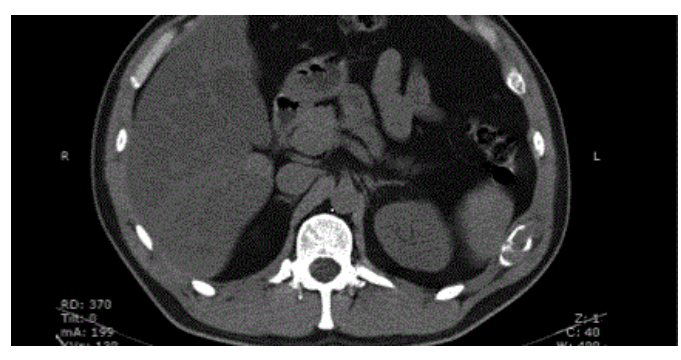

Figure 1: Computed tomography scan of thorax showing a welldefined, expansile lesion of the left 10th rib with breach of periosteum at places.

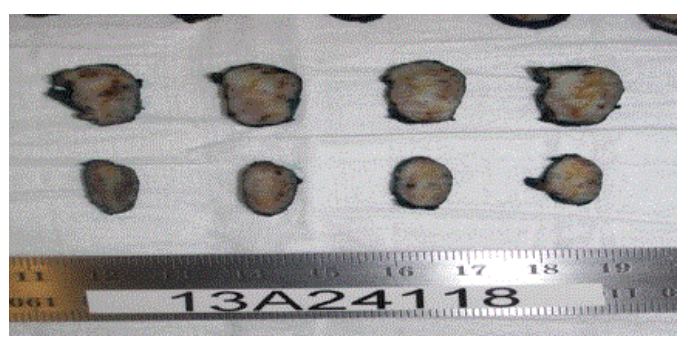

Figure 2: The left 10th rib is expanded by a firm white grey tumour with punctate foci of haemorrhage. 


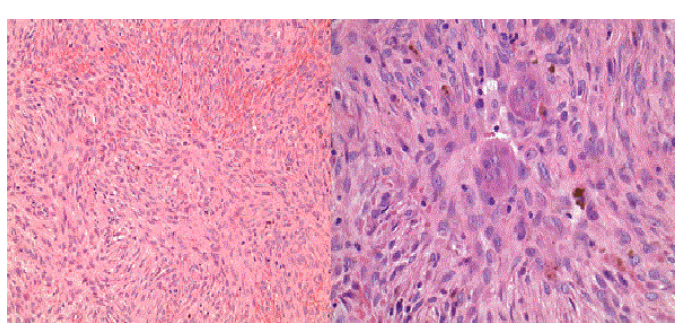

Figure 3: The tumour has storiform architecture with a proliferation of fibro-histiocytic cells and some multinucleated giant cells.

\section{Histology Findings}

Sections of the bone show a moderately cellular spindle cell tumour It has storiform pattern. No long fascicles are seen. There is entrapped woven bone within the lesion, along with scattered osteoclast-type giant cells. A breach of the cortex by tumour is identified but there is no local destruction of the adjacent soft tissue. The tumour cells have ovoid nuclei with no nuclear pleomorphism [1]. The cytoplasm is illdefined and elongated. Mitoses are inconspicuous. No necrosis is noted. The stroma contains hemosiderin -laden macrophages. There is no evidence of malignancy. The tumour cells are smooth muscle actin and focally CD10 positive. The Ki-67 index is less than $1 \%$. They are CD34, CD68, factor XIIIa and B-catenin negative. The features are those of Benign Fibrous Histiocytoma (BFH) of bone.

\section{Discussion}

Benign Fibrous Histiocytoma (BFH) of the bone is an uncommon entity and its occurrence in the rib being extremely rare [1,2]. Very few cases of benign fibrous Histiocytoma of the rib have been documented in literature (probably less than ten) [3].

Benign fibrous Histiocytoma is a condition of the bone, which does not have any specific age incidence, expect for the fact that it generally occurs in individuals greater than 20 years of age [4]. Differing opinion exists amongst pathologists as to the exact etiogenesis of the tumours. Opinions vary between calling it a true neoplasm, a developmental defect, or a reactive process.

The most common site involved is the Ilium, followed by the femur, the vertebrae, and tibia [5]. The importance of differentiating between Non Ossifying Fibroma (NOF) and BFH lies in the fact that BFH has a tendency to recur after curettage, while NOF does not. Additionally $\mathrm{BFH}$ has been known to behave in an aggressive manner with a potential for local spread and distant dissemination.

Clinically, it may be picked up as an asymptomatic finding while being investigated for other pathologies or patients report pain from the lesion, often of months or years duration [6]. Pain may be associated with pathological fracture. There may be some local tenderness, but no swelling or mass is seen, and there are no systemic symptoms. There is normally no impairment of the function of the nearby joint.

$\mathrm{X}$ ray image may show a lytic, loculated appearance with prominent sclerosis of the edges of the lesion. There is no matrix mineralization.
The zone of transition of the lesion is narrow. Cortical expansion and soft tissue invasion are rarely seen. On MRI scans, there is central low signal intensity with a surrounding rim of high signal on T1, and more uniform but somewhat variegated high signal intensity on $\mathrm{T} 2$ sequences, with the surrounding sclerotic bone having low signal intensity. Treatment options for benign fibrous Histiocytoma include wide resection of the tumour or curettage [7] and bone grafting.

Benign fibrous Histiocytoma is microscopically identical to metaphyseal fibrous defect, non-ossifying fibroma but benign fibrous Histiocytoma is usually seen in older age group and have low recurrence rates [8-10]. Occurrence of benign fibrous Histiocytoma of the rib is a very rare occurrence $[11,12]$. CT scan shows a moderately irregular lytic area with a prominent trabecular pattern and surrounding sclerotic bone [13].

Case reports still have a place in publication on account of their importance for clinical education and training of healthcare professionals. This rare case of benign [14,15] fibrous Histiocytoma being the case in point.

\section{References}

1. Clarke BE, Xipell JM, Thomas DP (1985) Benign fibrous histiocytoma of bone. Am J Surg Pathol 9: 806-815.

2. Bertoni F, Calderoni P, Bacchini P, Sudanese A, Baldini N, et al. (1986) Benign fibrous histiocytoma of bone. J Bone Joint Surg Am 68: 1225-1230.

3. Zia SA, Raza SH (2001) Benign fibrous histiocytoma of the rib. J Pak Med Assoc 51: 162-163.

4. Mondal SK (2010) Cytodiagnosis of benign fibrous histiocytoma of rib and diagnostic dilemma: a case report. Diagn Cytopathol 38: 457-460.

5. Reid R (1994) Atlas of Tumor Pathology, Fascicle 8, Third Series: Tumors of the Bones and Joints. Histopathol 24: 293.

6. Leonard FP (1995) Diagnosis of bone and joint disorders. JAMA 274: 508-509.

7. Destouet JM, Kyriakos M, Gilula LA (1980) Fibrous histiocytoma (fibroxanthoma) of a cervical vertebra. A report with a review of the literature. Skeletal Radiol 5: 241-246.

8. Matsuno T (1990) Benign fibrous histiocytoma involving the ends of long bones. Skeletal Radiol 19: 561-566.

9. Hermann G, Steiner GC, Sherry HH (1988) Case report 465: Benign fibrous histiocytoma (BFH). Skeletal Radiol 17: 195-198.

10. Xue L, Zhaowei M, Dong L, Jian T, Xinghua S (2014) Benign fibrous histiocytoma Clinical Nuclear Medicine 39: 837-841.

11. Ideguchi M, Kajiwara K, Yoshikawa K, Kato S, Fujii M, et al. (2009) Benign fibrous histiocytoma of the skull with increased intracranial pressure caused by cerebral venous sinus occlusion. J Neurosurg 111: 504-508.

12. Kishino M, Murakami S, Toyosawa S, Nakatani A, Ogawa Y, et al. (2005) Benign fibrous histiocytoma of the mandible. J Oral Pathol Med 34: 190-192.

13. Friedman L, Patel M, Lew E, Silberberg P (1989) Benign histiocytic fibroma of rib with CT correlation. Can Assoc Radiol J 40: 114-116.

14. Grohs JG, Nicolakis M, Kainberger F, Lang S, Kotz R (2002) Benign fibrous histiocytoma of bone: a report of ten cases and review of literature. Wien Klin Wochenschr 114: 56-63.

15. Ceroni D, Dayer R, De Coulon G, Kaelin A (2011) Benign fibrous histiocytoma of bone in a paediatric population: a report of 6 cases. Musculoskelet Surg 95: 107-114. 